„This is the peer reviewed version of the following article: René Panzer, Chris Guhrenz, Danny

Haubold, René Hübner, Nikolai Gaponik, Alexander Eychmüller and Jan J. Weigand (2017). Versatile Tri(pyrazolyl)phosphanes - Application as phosphorus precursors for the synthesis of highly emitting InP/ZnS quantum dots. Angewandte Chemie International Edition Engl. 2017 Nov 13; 56(46):1473714742, which has been published in final form at DOI:10.1002/anie.201705650.

This article may be used for non-commercial purposes in accordance with Wiley Terms and Conditions for Self-Archiving."

\title{
Versatile Tri(pyrazolyl)phosphanes - Application as phosphorus precursors for the synthesis of highly emitting InP/ZnS quantum dots
}

\author{
René Panzer, ${ }^{[a]}$ Chris Guhrenz, ${ }^{[b]}$ Danny Haubold, ${ }^{[b]}$ René Hübner, ${ }^{[c]}$ Nikolai Gaponik, ${ }^{[b]}$ Alexander \\ Eychmüller, ${ }^{*[b]}$ and Jan J. Weigand ${ }^{*[a]}$
}

\begin{abstract}
Tri(pyrazolyl)phosphanes $\left(5^{R 1, R 2}\right)$ are utilized as an alternative, cheap and low-toxic phosphorus source for the convenient synthesis of InP/ZnS quantum dots (QDs). From these precursors, remarkably long-term stable stock solutions (>6 months) of $P(O L A)_{3}$ $(\mathrm{OLAH}=$ oleylamine $)$ are generated from which the respective pyrazoles are conveniently recovered. $P(O L A)_{3}$ acts simultaneously as phosphorus source and reducing agent in the synthesis of highly emitting InP/ZnS core/shell QDs. These QDs are characterized by a spectral range between $530-620 \mathrm{~nm}$ and photoluminescence quantum yields (PL QYs) between 51-62\%. A proof-of-concept white light-emitting diode (LED) applying the InP/ZnS QDs as color conversion layer was built to demonstrate their applicability and processibility.
\end{abstract}

\section{INTRODUCTION}

In recent years InP-based QDs became the most highlighted candidates for a less-toxic surrogate for $\mathrm{Cd}_{-}{ }^{[1]}$ and $\mathrm{Pb}$-based ${ }^{[2]}$ photoelectric devices. ${ }^{[3]}$ Despite the improvements of InP-based QDs with regard to $P L Q Y$, narrow full-width at half-maximum (FWHM) and photo-stability, ${ }^{[4]}$ the pool of phosphorus precursors

[a] Prof. Dr. Jan J. Weigand, Rene Panzer, TU Dresden, Professur für Anorganische Molekülchemie 01062 Dresden (Germany)

E-mail: jan.weigand@tu-dresden.de

[b] Prof. Dr. Alexander Eychmüller, Prof. Dr. Nikolai Gaponik, Chris Guhrenz, Danny Haubold, TU Dresden

Professur für Physikalische Chemie 01062 Dresden (Germany)

E-mail: alexander.eychmueller@chemie.tu-dresden.de

[c] Dr. René Hübner

Institute of Ion Beam Physics and Materials Research

Helmholtz-Zentrum-Dresen-Rossendorf

01328 Dresden (Germany)

Supporting Information

( $\mathrm{P}_{1}$-sources) is still quite limited. Especially for applications on an industrial scale the search for a less expensive, harmless and more environmental friendly phosphorus precursor is of great interest. $\mathrm{PH}_{3}(\mathbf{1})^{[5]},(\mathrm{K} / \mathrm{Na})_{3} \mathrm{P} \quad(2)^{[6]}$ and $\mathrm{P}_{4}{ }^{[7]}$ are used as phosphorus source for the synthesis of III-V QDs, however, show a series of severe drawbacks. Nowadays most commonly used is the hazardous and expensive tris(trimethylsilyl)phosphane $\left(\left(\mathrm{Me}_{3} \mathrm{Si}\right)_{3} \mathrm{P}, 3\right)^{[4 \mathrm{~b}, 8]}$ which also requires special handling and storage precautions (Scheme 1). Intensive research deals with the exploration of other suitable $\mathrm{P}_{1}$-Sources ${ }^{[5 \mathrm{~d}, 5 \mathrm{e}, 6 \mathrm{~b}, 7 \mathrm{~b}, 9]}$ but besides these efforts, it appears that only tris(dimethyl)aminophosphane $\left(\mathrm{P}_{\cup}\left(\mathrm{NMe}_{2}\right)_{3}, 4\right)$ has been

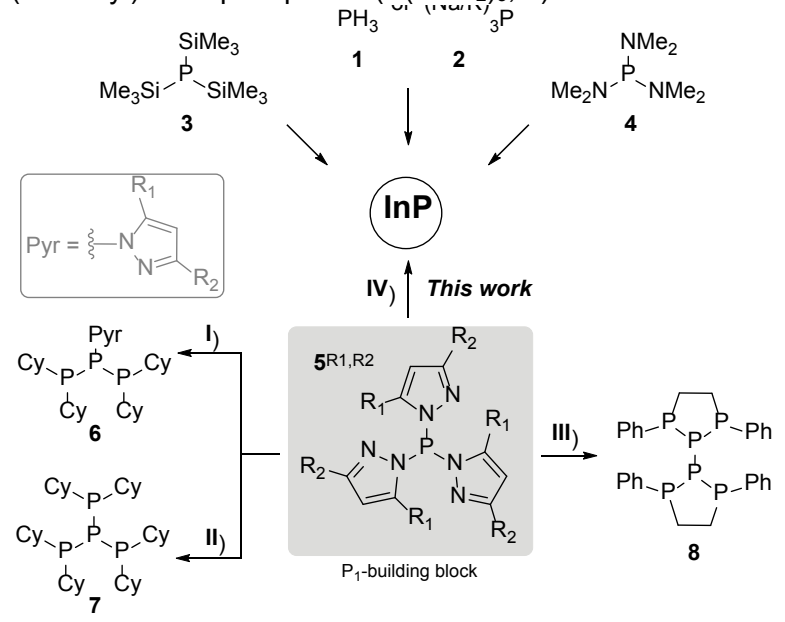

Scheme 1. Application of 1-5 for the synthesis of InP QDs and application of $5^{\mathrm{Me}, \mathrm{Me}}$ in $\mathrm{P}-\mathrm{P}$ bond formation reactions; I) $2 \mathrm{Cy}_{2} \mathrm{PH}(\mathrm{Cy}=$ cyclohexyl), $-2 \mathrm{PyrH}$, $\mathrm{CH}_{3} \mathrm{CN}$; II) $3 \mathrm{Cy}_{2} \mathrm{PH}, \quad \mathrm{CH}_{3} \mathrm{CN}, \quad \mathrm{Pyr}=3,5$-dimethyl-1-pyrazolyl; III) 5 $\mathrm{PhPH}\left(\mathrm{CH}_{2}\right)_{2} \mathrm{PHPh}, 45^{\mathrm{Me}, \mathrm{Me}},-\mathrm{PhP}(\mathrm{Pyr})\left(\mathrm{CH}_{2}\right)_{2} \mathrm{P}(\mathrm{Pyr}) \mathrm{Ph},-10 \mathrm{PyrH}, \mathrm{CH}_{3} \mathrm{CN}$; IV) $\mathrm{InCl}_{3}, \mathrm{ZnCl}_{2}$, OLAH, - $3 \mathrm{PyrH}$.

applied successfully for the synthesis of highly emitting $\operatorname{lnP} / \mathrm{ZnS}$ core/shell QDs so far. ${ }^{[10]}$ Tessier et al. ${ }^{[11]}$ and Buffard et al. ${ }^{[12]}$ reported independently that $\mathbf{4}$ undergoes an in situ transamination reaction with OLAH as key solvent for the $\operatorname{InP}$ core synthesis to yield $\mathrm{P}(\mathrm{OLA})_{3}$ and $\mathrm{HNMe}_{2}$. The formed $\mathrm{P}(\mathrm{OLA})_{3}$ acts simultaneously as phosphorus source and reducing agent during the formation of the InP QDs. ${ }^{[11-12]}$ 
In our continuous efforts to use pyrazolyl-substituted phosphorus compounds as efficient $P_{1}$-source we demonstrated that the methyl-derivative of $5^{\mathrm{R} 1, \mathrm{R} 2}\left(\mathrm{R}_{1,2}=\mathrm{Me}\right)$ acts as a remarkably efficient $\mathrm{P}_{1}$-building block in $\mathrm{P}-\mathrm{P}$ bond forming reactions. ${ }^{[13]}$ Thus, the reaction of $5^{\mathrm{Me}, \mathrm{Me}}$ with $\mathrm{Cy}_{2} \mathrm{PH}$ (Scheme 1) gives access to triphosphane 6 (I) and isotetraphosphane 7 (II) depending on the applied stoichiometries. ${ }^{[14]} \mathrm{We}$ also reported the reaction of $\mathbf{5}^{\mathrm{Me}, \mathrm{Me}}$ with 1,2-bis(phenylphosphino)ethane which yields hexaphosphane 8 and 1,2-bis(phenylpyrazolylphosphino)ethane in an unexpected P-N/P-P bond metathesis reaction (III). ${ }^{[15]}$ Those versatile reactivities are attributed to the labile $\mathrm{P}-\mathrm{N}$ bonds of the pyrazolyl-subsituted phosphanes. Thus, we envisioned that derivatives $5^{\mathrm{R} 1, \mathrm{R} 2}$ should be suitable phosphorus precursors for the synthesis of high-quality InP QDs (IV). Herein, we report on the facile access to a variety of tri(pyrazolyl)phosphanes $5^{R 1, R 2}$ which are suitable for the generation of a long-term stable stock solution of $\mathrm{P}(\mathrm{OLA})_{3}$ (>6 months) and their application for the synthesis of high-quality InP QDs.

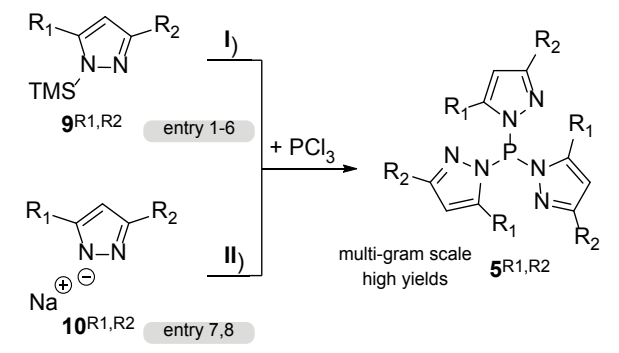

Scheme 2. Synthesis of tri(pyrazolyl)phosphanes $5^{\mathrm{R} 1, \mathrm{R} 2}$ according to method $\mathrm{I}$ ) neat, $16 \mathrm{~h}, \mathrm{RT}$ or II) THF, $\mathbf{5}^{\mathrm{iPr}, \mathrm{BBu}}(16 \mathrm{~h}, \mathrm{RT})$ and for $\mathbf{5}^{\mathrm{tBu}, \mathrm{tBu}}(24 \mathrm{~h}$, reflux).

Tri(pyrazolyl)phosphanes $5^{\mathrm{R} 1, \mathrm{R} 2}$ are obtained via a modified procedure of Fischer et al. ${ }^{[16]}$ from the reaction of $\mathrm{PCl}_{3}$ with either trimethylsilylpyrazoles $9^{R 1, R 2}$ (Scheme 2, I; Table 1, entries 1-6) for less sterically demanding substituted phosphanes or from the sodium salts $10^{\mathrm{R} 1, \mathrm{R} 2}$ for sterically encumbered derivatives (Scheme 2, II; Table 1, entries 7 and 8). Both reaction pathways provide high yields (88-98\%) and the compounds can be obtained on a multi-gram scale. The reaction involving derivatives of $9^{\mathrm{R} 1, \mathrm{R} 2}$ with $\mathrm{PCl}_{3}$ is best performed under solvent-free conditions and analytically pure products are conveniently obtained after removal of all volatiles under vacuum. Dropwise addition of $\mathrm{PCl}_{3}$ to a cooled solution of sodium pyrazolates $10^{\mathrm{R} 1, \mathrm{R} 2}$ in THF affords after stirring at room temperature for $16 \mathrm{~h}\left(\mathbf{1 0}^{\mathrm{iPr}, \mathrm{BB} u}\right)$ or refluxing for $24 \mathrm{~h}\left(10^{\mathrm{iPr}, \mathrm{BBu}}\right)$ the sterically demanding phosphanes $10^{\mathrm{iPr}, t \mathrm{Bu}}$ and $10^{\mathrm{tBu}, \mathrm{tBu}}$, respectively. ${ }^{[17]}$

Compared to the reaction involving 4 as $\mathrm{P}_{1}$-source, the dissolution of tri(pyrazolyl)phosphanes $5^{\mathrm{R} 1, \mathrm{R} 2}$ (Table 1 , entries 1-7) in OLAH yields aminophosphanes 11 and the corresponding pyrazoles (Scheme 3; SI, Scheme S1). No reaction is observed in the case of $\mathbf{5}^{\mathrm{tBu}, \mathrm{tBu}}$ (Table 1, entry 8; SI, Figure S2) even after prolonged heating. We attribute this observation to the steric demand of the $t \mathrm{Bu}$ substituents. A substantial improvement compared to the synthesis with $\mathbf{4}$ is the drastically reduced toxicity of the starting material and that most of the liberated pyrazoles can be recycled and reused for the synthesis of $5^{\mathrm{R} 1, \mathrm{R} 2}$. This contributes positively towards a desirable waste-management. The prevention of high amounts of gaseous, corrosive and flammable dimethylamine reduces the hazardous and environmental risks drastically as well. For derivatives $5^{, C F 3}$ and $5, C F 3$ the recovery of the corresponding pyrazoles is problematic since their increased acidity leads to an adduct formation with the solvent OLAH (SI, Figure S1).[17] However, the redox-reaction of 11 with $\mathrm{InCl}_{3}$ yields three equivalents of the phosphonium salt $12[\mathrm{Cl}]$ and $\operatorname{InP}$ (Scheme 3).

Table 1. Yields and ${ }^{31} \mathrm{P}-\left\{{ }^{1} \mathrm{H}\right\}$ NMR chemical shifts of tri(pyrazolyl)phosphanes $5^{\mathrm{R} 1, \mathrm{R} 2}$ obtained according to Scheme 2 .

\begin{tabular}{cccccc}
\hline $\begin{array}{c}\mathbf{5}^{\mathrm{R} 1, \mathrm{R} 2} \\
\text { entry }\end{array}$ & Method & $\mathbf{R}_{\mathbf{1}}$ & $\mathbf{R}_{\mathbf{2}}$ & $\begin{array}{c}\text { Yield } \\
{[\%]}\end{array}$ & $\begin{array}{c}\boldsymbol{\delta}\left({ }^{31} \mathbf{P}\right) \\
{[\mathrm{ppm}]}\end{array}$ \\
\hline $\mathbf{1 a}$ & $\mathbf{I}$ & $\mathrm{H}$ & $\mathrm{H}$ & 92 & 61.1 \\
$\mathbf{2 b}$ & $\mathbf{I}$ & $\mathrm{Me}$ & $\mathrm{Me}$ & 98 & 71.9 \\
$\mathbf{3 c}$ & $\mathbf{I}$ & $i \mathrm{Pr}$ & $i \mathrm{Pr}$ & 98 & 69.4 \\
$\mathbf{4 f}$ & $\mathbf{I}$ & $\mathrm{Ph}$ & $\mathrm{Ph}$ & 88 & 74.8 \\
$\mathbf{5 q}$ & $\mathrm{I}$ & $\mathrm{H}$ & $\mathrm{CF}_{3}$ & 96 & 63.9 \\
$\mathbf{6 h}$ & $\mathbf{I}$ & $\mathrm{Me}$ & $\mathrm{CF}_{3}$ & 95 & 76.4 \\
$\mathbf{7 d}$ & $\mathrm{II}$ & $i \mathrm{Pr}$ & $t \mathrm{Bu}$ & 84 & 66.8 \\
$\mathbf{8 e}$ & $\mathrm{I}$ & $t \mathrm{Bu}$ & $t \mathrm{Bu}$ & 90 & 80.6 \\
\hline
\end{tabular}

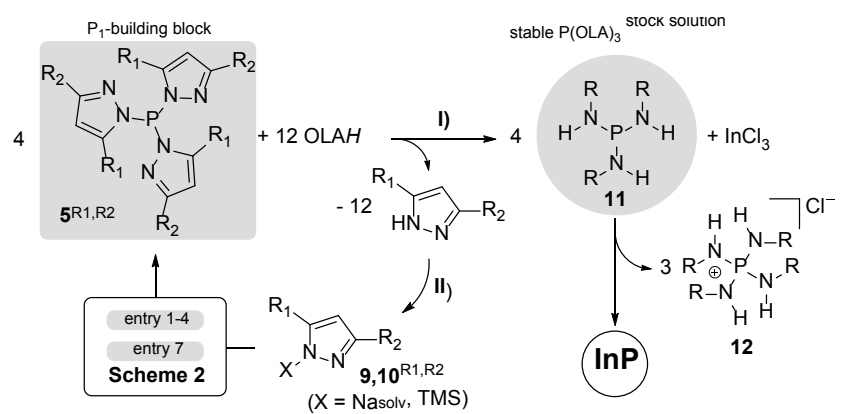

Scheme 3. Proposed reaction pathway for the synthesis of InP QDs applying tri(pyrazolyl)phosphanes $5^{\mathrm{R} 1, \mathrm{R} 2}, \mathrm{R}=\mathrm{C}_{18} \mathrm{H}_{35} ;$ I $) 50^{\circ} \mathrm{C}$, vacuum; II) $9^{\mathrm{R} 1, \mathrm{R} 2}\left(12 \mathrm{NEt}_{3}\right.$, $\left.12 \mathrm{TMSCl} \mathrm{Et}_{2} \mathrm{O}, \mathrm{RT}\right), 10^{\mathrm{R} 1, \mathrm{R} 2}(12 \mathrm{NaH}, \mathrm{THF}, \mathrm{RT})$.

Tessier et al. ${ }^{[11]}$ and Buffard et al. ${ }^{[12]}$ propose different reaction pathways, but both point out that $\mathbf{1 1}$ is the reactive species for the formation of $\mathrm{InP} Q \mathrm{QDs}$. According to our investigations the dissolution of $5^{\mathrm{Me}, \mathrm{Me}}$ under reduced pressure yields a remarkably stable solution of 11 . The formed by-product 3,5-dimethylpyrazole is conveniently and completely removed via sublimation and can be recovered in high yields $(>92 \%)$. The obtained clear, colorless solution is stable for several months ( $>6$ months) when stored under inert atmosphere. Thus, it represents a handy stock solution which only contains minor amounts of the tautomer $11^{\circ}$ and the amino-bridged diphosphane 13 (Figure 1).

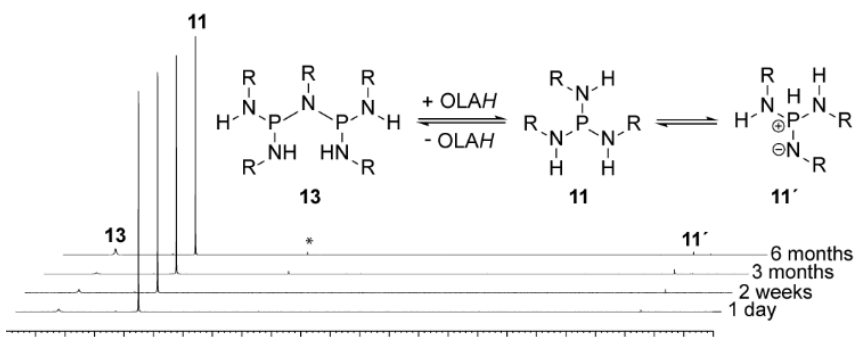

$\begin{array}{llllllllllll}110 & 100 & 90 & 80 & 70 & 60 & 50 & 40 & 30 & 20 & 10 \mathrm{ppm}\end{array}$

Figure $1 .{ }^{31} \mathrm{P}$-NMR spectra of the $\mathrm{P}(\mathrm{OLA})_{3}$ stock solution after 1 day, 2 weeks, 3 and 6 months showing the long-term stability of the stock solution. 
Similarly to $\mathbf{4}, \mathbf{5}^{\mathrm{Me}, \mathrm{Me}}$ can also be applied for the in situ synthesis of InP QDs. For the hot injection technique we can now either rapidly inject a hot solution of phosphane $5^{\mathrm{Me}, \mathrm{Me}}$ in OLAH under static vacuum (synthetic route $1, \mathbf{S R} 1$ ) or inject the previously prepared $0.5 \mathrm{mmol}$ stock solution of aminophosphane $\mathrm{P}(\mathrm{OLA})_{3}$ in OLAH (synthetic route 2, SR2). ${ }^{[17]}$ Both methods have been performed in our labs and are compared in the following discussion. We found, that the application of the $\mathrm{P}(\mathrm{OLA})_{3}$ stock solution (SR2) contributes more positively to the development of a well defined LaMer-type growth for InP QDs, approaching more conveniently the narrow FWHM of the established II-VI and IV-VI semiconductor QDs. The growth of the QDs can be evidenced for both cases by the red-shift in the absorption spectra and the color change of the QD solutions (Figure 2A). As can be seen from the absorption spectra in Figure $2 \mathrm{~A}$ the characteristic excitonic feature of the InP QDs at $\sim 450 \mathrm{~nm}$ starts to develop after $10 \mathrm{~min}$ using static vacuum for the removal of the pyrazole (SR1). The growth of the QDs slows down after 60 min reaching a maximum at $\sim 560 \mathrm{~nm}$, which exhibits generally the complete consumption of the phosphorus precursor. However, monitoring the reaction by ${ }^{31} \mathrm{P}$-NMR spectroscopy reveals that after $90 \mathrm{~min}$ reaction time there is still compound $\mathbf{1 1}$ present (Figure 2B), possibly implying an interfering effect of the released pyrazole. In contrast, applying the prior synthesized stock solution (SR2), the reaction proceeds remarkably clean (Figure 2D), indicating a better separation of nucleation and growth and, therefore, a more LaMer-type reaction. ${ }^{[18]}$ The results for the first absorption peak maximum (Figure $2 \mathrm{C}$ ) are comparable with prior publications using $\mathrm{P}\left(\mathrm{NMe}_{2}\right)_{3},{ }^{[10 \mathrm{~b}, 11-12]}$ but show slower reaction kinetics. The resulting InP QDs are not luminescent as already observed for the synthesis using $\mathrm{P}\left(\mathrm{NMe}_{2}\right)_{3}$ as $\mathrm{P}_{1}$-source. However, in order to get highly fluorescent QDs a passivating ZnS shell can be grown on the core QDs. To guarantee a successful ZnS overcoating of the InP cores and to exhibit a high stability and performance an excess of zinc chloride, elevated temperatures $\left(260^{\circ} \mathrm{C}\right)$ and a long shelling time $(4 \mathrm{~h})$ were chosen. ${ }^{[17]}$ Due to an undesired side reaction with the couple product $\left[\mathrm{P}(\mathrm{OLA})_{4}\right] \mathrm{Cl}$ (12), 1Dodecanethiol (DDT) is used in excess, as sulfur source. Detailed ${ }^{31} \mathrm{P}-N M R$ investigations revealed that DDT reacts with the phosphonium salt 12 to thiophosphorictrioleylamine 14 under the harsh reaction conditions (Figure 2D, (III) and SI, Figure S3). ${ }^{[17]}$ After successful ZnS shelling highly emitting QDs displaying a green to red emission are obtained. As can be seen from Figure 3 the emission wavelength can be tuned between $\sim 535-620 \mathrm{~nm}$ with a FWHM of $66-81 \mathrm{~nm}$. The corresponding absorption spectra of the $\mathrm{InP} / \mathrm{ZnS} \mathrm{QDs}$ are given in Figure $\mathrm{S} 5^{[17]}$ showing an increase of the optical density at $\sim 400 \mathrm{~nm}$ resulting from the $\mathrm{ZnS}$ shell. Absolute PL QYs of the core/shell QDs are reaching $51-62 \%$. In

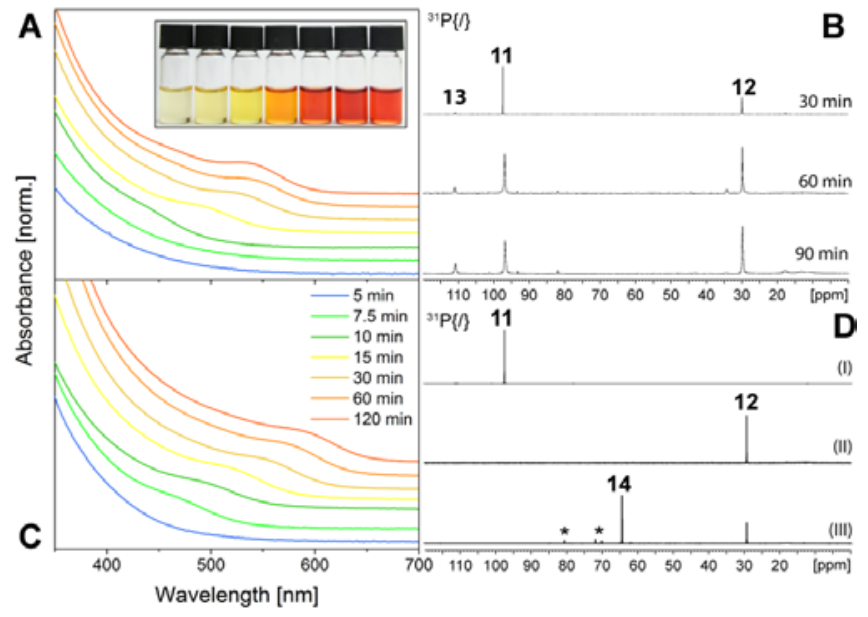

comparison, applying $\mathrm{P}(\mathrm{Pyr})_{3}$ in situ (SR1) results also in the formation of non-fluorescing InP QDs which, after passivation with ZnS and development of a type-I band alignment, gain PL QYs ranging between $33-58 \%$ covering the same spectral range (530-620 nm, SI, Figure S6). ${ }^{[17]}$ The broader variation in PL QYs and FWHMs (59-90 nm) may be explained by the lower reaction rates causing formation of a larger number of trap states. The results for both synthetic techniques are summarized in Table S1. ${ }^{[17]}$ The successful growth of the ZnS shell was evidenced by transmission electron microscopy (TEM). In Figure 3 representative bright-field TEM images of the pure InP cores $(A)$ and the resulting InP/ZnS core/shell QDs (B-C) are displayed. According to TEM, the average size of the pure $\operatorname{InP} Q D$ s is between $\sim 3.2 \mathrm{~nm}$ (15 min growth time) and $\sim 6.5 \mathrm{~nm}$ (60 min growth time). As a result of $\mathrm{ZnS}$ shelling the spherical InP QDs (Figure 3A) obtain a tetrahedral shape (Figures 3B-C). HRTEM measurements of the $\operatorname{InP} / \mathrm{ZnS} \mathrm{QDs}$ show continuous lattice
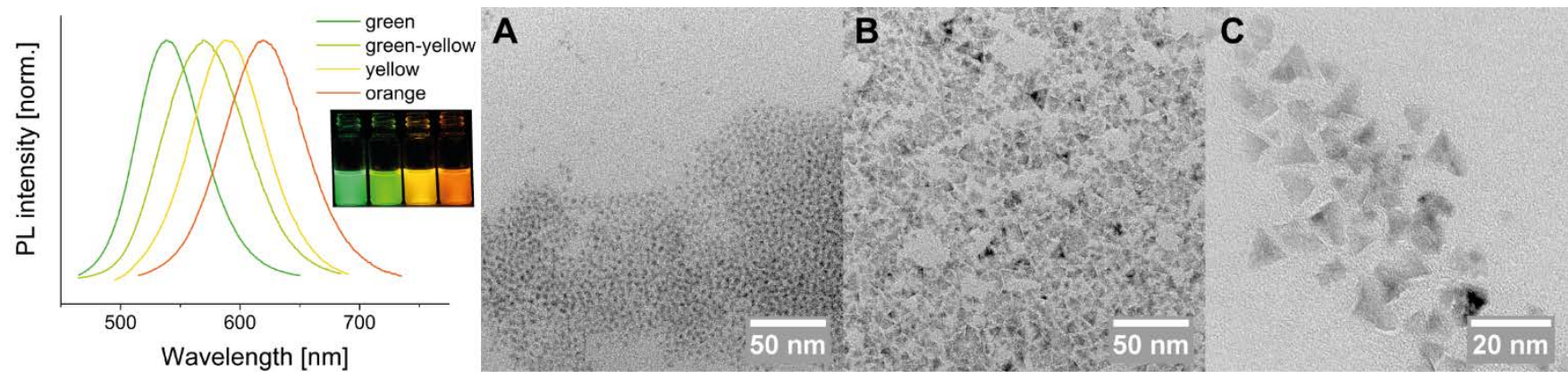


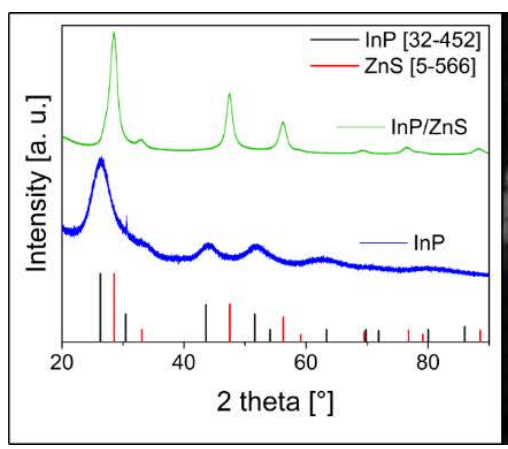

Figure 2. Temporal evolution of the absorption spectra of the InP QDs using SR1 (A) or SR2 (C). Inset B shows the stacked ${ }^{31} \mathrm{P}-\mathrm{NMR}$ spectra after 30,60 , and 90 min reaction time applying SR1. Inset D shows the stacked ${ }^{31} \mathrm{P}-\mathrm{NMR}$ spectra following SR2: stock solution (I), after 15 min reaction time (II), after shelling with DDT (III). 14 occurs from a side reaction of DDT with 12.

fringes throughout the whole nanoparticle which indicates a high crystallinity of the final core/shell material. The measured latticefringe distance of $0.32 \mathrm{~nm}$ corresponds well with the (111) lattice plane of the ZnS zinc blende structure (JCPDS \# 5-566). The comparison of the X-ray diffraction (XRD) patterns of the InP and the InP/ZnS QDs exhibits also the successful ZnS shelling of the InP cores (Figure 4, left). In particular, the XRD pattern of the InP QDs depicts the 111, 220, and 311 Bragg reflections of the cubic zinc blende structure. After shelling Bragg reflexes of the thick $\mathrm{ZnS}$ coating superimpose the diffraction maxima of the InP cores (Figure 4, left). Hence, only the most prominent 111 reflex of the InP/ZnS QDs shows a shoulder at lower diffraction angles to the peak maximum (enlargement in SI, Figure S7). ${ }^{[17]}$ The additional shift of the $\operatorname{lnP} 111$ reflex to higher 2 theta values might result from the incorporation of zinc into the $\operatorname{InP}$ lattice leading to an intermixed $\ln (Z n) P$ core structure. Previous reports already mentioned that during the growth of InP QDs zinc can be implemented into the QD lattice. ${ }^{[19]}$ ICP-OES measurements of our InP QDs revealed an element composition of $\mathrm{In}: \mathrm{P}: \mathrm{Zn}=$ $0.47: 0.46: 0.07$ indicating no major assembly of zinc before shelling. Nevertheless, an alloyed In(Zn)P QD core allows better lattice engineering for the subsequent strain-free, epitaxial shell

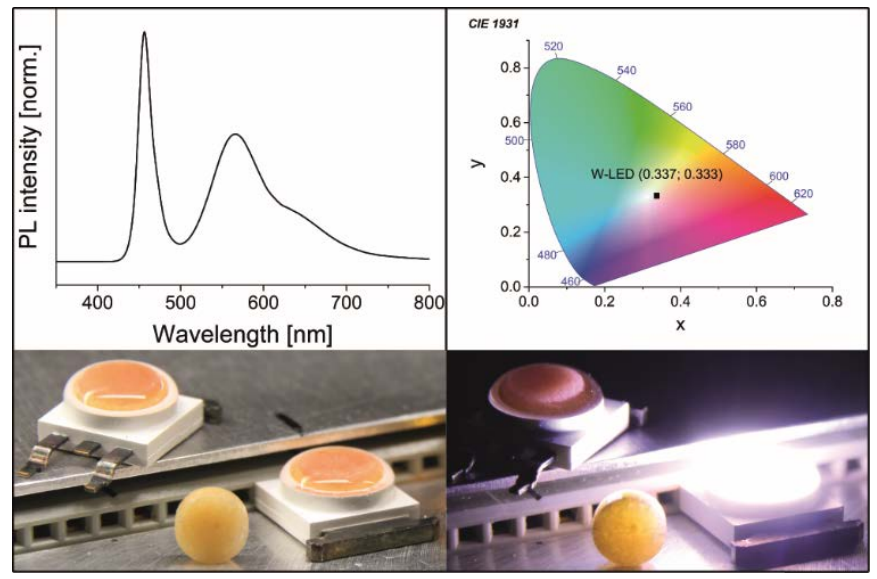

growth as demonstrated for $\mathrm{ZnSe}_{\mathrm{z}} \mathrm{S}_{\mathrm{z}-1}{ }^{[19 \mathrm{~b}]}$

Figure 3. PL spectra of InP/ZnS QDs synthesized via SR2 (left) and TEM brightfield-images of $(A) \ln P$ and $(B-C) \ln P / Z n S$ QDs.

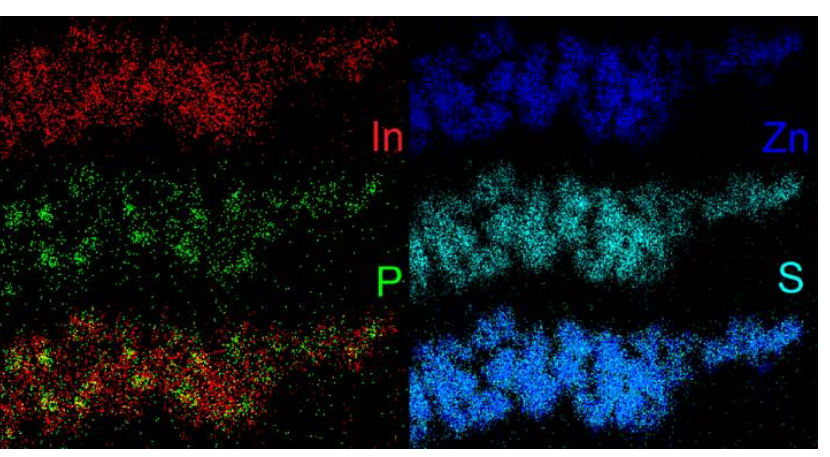

Figure 4. XRD of $\operatorname{InP}$ and $\operatorname{InP} / Z n S$ QDs (left); HAADF-STEM $i$ of the synthesized $\operatorname{InP} / \mathrm{ZnS} \mathrm{QDs}$ and the corresponding EDX data for the distribution of $\mathrm{In}, \mathrm{Zn}, \mathrm{P}$, and $\mathrm{S}$ (right).

In particular, the implemented zinc reduces the lattice mismatch resulting in higher PL QYs of the final core/shell structure. Figure 4, right shows a high-angle annular dark-field scanning transmission electron microscopy (HAADF-STEM) image of the resulting InP/ZnS QDs. From the corresponding EDXS (energydispersive X-ray spectroscopy) data, obtained for the rectangular region marked in the HAADF-STEM image, successful ZnS shelling is evidenced. It is, however; not possible to observe separated InP cores. Rather indium and zinc seem to be distributed over the whole inner QD core. Besides true intermixing of both elements, as discussed above, 2-dimensional data recording in the TEM from the 3-dimensional tetrahedrally shaped QDs leads to simultaneous acquisition of $I n$ and $P$ from the core region as well as of $\mathrm{Zn}$ and $\mathrm{S}$ from the corresponding shell volume in front and behind the core. Furthermore it should be mentioned that next to phosphorus rich regions high amounts of indium and zinc are observed. Due to the high reaction temperature $\left(260^{\circ} \mathrm{C}\right)$, interdiffusion and partial ion exchange of $\mathrm{In}^{3+}$ and $\mathrm{Zn}^{2+}$ during $\mathrm{ZnS}$ shelling is resulting in an alloyed interface layer between the $\mathrm{In}(\mathrm{Zn}) \mathrm{P}$ core and the pure $\mathrm{ZnS}$ shell. This is in agreement with published XPS (X-ray photoelectron spectroscopy) data following a two-step approach for the synthesis of InP/ZnS QDs. ${ }^{[20]}$

Figure 5. PL spectra of the manufactured white LED (top left) with the corresponding CIE 1931 plot (top right); LED under ambient conditions (bottom left) and in operation (bottom right)

Additional XAS (X-ray absorption spectroscopy) measurements by $\mathrm{Cho}$ et al. ${ }^{[21]}$ revealed that the $\mathrm{In}-\mathrm{Zn}$ bond becomes more pronounced with increasing $\mathrm{ZnS}$ shelling time. This was attributed to additional bonding between the slow growing $\mathrm{InP} / \mathrm{ZnS}$ core/shell interface.

Due to the lower toxicity in comparison to commonly used Cdbased materials, highly emitting InP/ZnS QDs are very attractive for solid state lighting applications. ${ }^{[\mathrm{b}, 22]}$ As suitable demonstrator we produced a proof-of-concept white LED and mounted it into a conventional pocket torch (SI, Figure S8). ${ }^{[17]}$ According to a previous publication we incorporated the resulting green- and orange-emitting $\mathrm{InP} / \mathrm{ZnS}$ QDs into a protective $\mathrm{KCl}$ salt matrix. ${ }^{[23]}$ Pressing the NC-loaded salt under cold flow conditions at $2.2 \mathrm{GPa}$ results in composite materials which can be used as color conversion layers when stacked on top of a commercially available blue-emitting LED (Figure 5, bottom). The 
corresponding PL spectrum and CIE diagram ( $x=0.337, y=$ 0.333 ) of the white LED are shown in Figure 5 (top).

In summary, with the advantageous synthesis of a library of novel tri(pyrazolyl)phosphanes $5^{R 1, R 2}$, we introduced versatile $\mathrm{P} 1$ building blocks for the direct synthesis of InP core QDs. Most importantly the combination of a convenient access to a long-term stable $\mathrm{P}(\mathrm{OLA})_{3}$ stock solution (> 6 month) with a high-yield recovery of the pyrazole (> $90 \%$ ) provides an auspicious new approach for the synthesis of InP QDs. A possible extension to other phosphide-based QDs such as AIP, GaP, $Z n_{3} P_{2}$ or $C_{1} P_{2}$ is currently addressed. After shelling the resulting $\mathrm{InP} / \mathrm{ZnS}$ core/shell QDs are covering a broad spectral range from 530-620 $\mathrm{nm}$ showing high PL QYs up to $60 \%$. Applying the highly emitting InP/ZnS QDs as color conversion layers, we manufactured a proof-of-concept white LED pocket torch showing the applicability and processibility of the core/shell QDs. The innovative access to a storable $\mathrm{P}(\mathrm{OLA})_{3}$ stock solution is given and leads to the development of a defined LaMer-type growth for InP QDs. Moreover, an extension to $\mathrm{As}(\mathrm{Pyr})_{3}$ is of great interest and will be in the focus of our forthcoming paper.

\section{Acknowledgements}

R.P. and J.J.W. gratefully acknowledge financial support from the European Research Council (ERC) (SynPhos, project number 307616). C.G., N.G. and A.E. gratefully acknowledge financial support from the M-ERA.NET Network (ICENAP, project number GA 1289/3-1) and the European Research Council (AEROCAT, ERC-2013-AdG). D.H. and A.E. gratefully acknowledge the financial support from the Graduate Academy of Technische Universität Dresden as well as the Excellence Initative by the German Federal and by the Deutsche Forschungsgemeinschaft through the research training group Nano- and biotechnologies for packaging of electronic systems (project number DFG 1401/2) Furthermore, the use of HZDR Ion Beam Center TEM facilities and the funding of TEM Talos by the German Federal Ministry of Education of Research (BMBF), Grant No. $03 S F 0451$ in the framework of HEMCP are gratefully acknowledged.

Keywords: InP/ZnS • Phosphorus • Quantum Dots • Hot Injection $•$ Waste Prevention $\cdot$ Oleylamine.

[1] a) E. Jang, S. Jun, H. Jang, J. Lim, B. Kim, Y. Kim, Adv. Mater. 2010, 22, 3076-3080; b) N. Gaponik, D. V. Talapin, A. L. Rogach, K. Hoppe, E. V. Shevchenko, A. Kornowski, A. Eychmüller, H. Weller, The Journal of Physical Chemistry B 2002, 106, 7177-7185.

[2] a) D. V. Talapin, C. B. Murray, Science 2005, 310, 86-89; b) H. Du, C. Chen, R. Krishnan, T. D. Krauss, J. M. Harbold, F. W. Wise, M. G. Thomas, J. Silcox, Nano Lett. 2002, 2, 1321-1324; c) R. Y. Wang, J. P. Feser, J.-S. Lee, D. V. Talapin, R. Segalman, A. Majumdar, Nano Lett. 2008, 8, 2283-2288.

[3] a) S. Tamang, C. Lincheneau, Y. Hermans, S. Jeong, P. Reiss, Chem. Mater. 2016, 28, 2491-2506; b) V. Brunetti,
H. Chibli, R. Fiammengo, A. Galeone, M. A. Malvindi, G. Vecchio, R. Cingolani, J. L. Nadeau, P. P. Pompa, Nanoscale 2013, 5, 307-317; c) P. Reiss, M. Carrière, C. Lincheneau, L. Vaure, S. Tamang, Chem. Rev. 2016, 116, 10731-10819.

[4] a) J. P. Park, J.-J. Lee, S.-W. Kim, Scientific Reports 2016 6, 30094; b) S. Kim, T. Kim, M. Kang, S. K. Kwak, T. W. Yoo, L. S. Park, I. Yang, S. Hwang, J. E. Lee, S. K. Kim, S.W. Kim, J. Am. Chem. Soc. 2012, 134, 3804-3809.

[5] a) N. Mordvinova, A. Vinokurov, S. Dorofeev, T. Kuznetsova, K. Znamenkov, J. Alloys Compd. 2014, 582, 43-49; b) N. Mordvinova, A. Vinokurov, T. Kuznetsova, O. I. Lebedev, S. Dorofeev, Dalton Trans. 2017, 46, 12971303; c) A. A. Vinokurov, S. G. Dorofeev, K. O. Znamenkov, A. V. Panfilova, T. A. Kuznetsova, Mendeleev Commun. 2010, 20, 31-32; d) F. Zan, J. Ren, J. Mater. Chem. 2012, 22, 1794-1799; e) L. Li, M. Protière, P. Reiss, Chem. Mater. 2008, 20, 2621-2623.

[6] a) S. S. Kher, R. L. Wells, Chem. Mater. 1994, 6, 20562062; b) K.-W. Jun, P. K. Khanna, K.-B. Hong, J.-O. Baeg, Y.-D. Suh, Mater. Chem. Phys. 2006, 96, 494-497.

[7] a) E. Bang, Y. Choi, J. Cho, Y.-H. Suh, H. W. Ban, J. S. Son, J. Park, Chem. Mater. 2017, 29, 4236-4243; b) P. Ung Thi Dieu Thuy; Tran Thi Thuong Huyen; Nguyen Quang Liem; Reiss, Mater. Chem. Phys. 2008, 112, 3.

[8] a) L. Li, P. Reiss, J. Am. Chem. Soc. 2008, 130, 1158811589; b) Y. Altıntas, M. Y. Talpur, M. Ünlü, E. Mutlugün, The Journal of Physical Chemistry C 2016, 120, 7885-7892; c) S. Xu, J. Ziegler, T. Nann, J. Mater. Chem. 2008, 18, 2653-2656.

[9] Z. Liu, A. Kumbhar, D. Xu, J. Zhang, Z. Sun, J. Fang, Angew. Chem. Int. Ed. 2008, 47, 3540-3542.

[10] a) M. D. Tessier, D. Dupont, K. De Nolf, J. De Roo, Z. Hens, Chem. Mater. 2015, 27, 4893-4898; b) W.-S. Song, H.-S. Lee, J. C. Lee, D. S. Jang, Y. Choi, M. Choi, H. Yang, J. Nanopart. Res. 2013, 15, 1750.

[11] M. D. Tessier, K. De Nolf, D. Dupont, D. Sinnaeve, J. De Roo, Z. Hens, J. Am. Chem. Soc. 2016, 138, 5923-5929.

[12] A. Buffard, S. Dreyfuss, B. Nadal, H. Heuclin, X. Xu, G. Patriarche, N. Mézailles, B. Dubertret, Chem. Mater. 2016, 28, 5925-5934.

[13] K.-O. Feldmann, J. J. Weigand, Angew. Chem. Int. Ed. 2012, 51, 6566-6568.

[14] K.-O. Feldmann, R. Fröhlich, J. J. Weigand, Chem. Commun. 2012, 48, 4296-4298.

[15] K.-O. Feldmann, J. J. Weigand, J. Am. Chem. Soc. 2012 134, 15443-15456.

[16] a) S. Fischer, L. K. Peterson, J. F. Nixon, Can. J. Chem. 1974, 52, 3981-3985; b) S. Fischer, J. Hoyano, L. K. Peterson, Canadian Chem. Journal 1976, 54, 2710-2714. [17] see Supporting Information doi: $X X X X X X X X X X X X X X X X$.

[18] a) T. Sugimoto, J. Colloid Interface Sci. 2007, 309, 106-118; b) T. Sugimoto, Adv. Colloid Interface Sci. 1987, 28, 65-108.

[19] a) H. Virieux, M. Le Troedec, A. Cros-Gagneux, W.-S. Ojo, F. Delpech, C. Nayral, H. Martinez, B. Chaudret, J. Am. 
Chem. Soc. 2012, 134, 19701-19708; b) F. Pietra, L. De Trizio, A. W. Hoekstra, N. Renaud, M. Prato, F. C. Grozema, P. J. Baesjou, R. Koole, L. Manna, A. J. Houtepen, ACS Nano 2016, 10, 4754-4762.

[20] K. Huang, R. Demadrille, M. G. Silly, F. Sirotti, P. Reiss, O. Renault, ACS Nano 2010, 4, 4799-4805.

[21] D.-Y. Cho, L. Xi, C. Boothroyd, B. Kardynal, Y. M. Lam, Scientific Reports 2016, 6, 22818.

[22] a) P. Ramasamy, B. Kim, M.-S. Lee, J.-S. Lee, Nanoscale 2016, 8, 17159-17168; b) R. Xie, K. Chen, X. Chen, X. Peng Nano Research 2008, 1, 457-464; c) D. Li, L. Peng, Z. Zhang, Z. Shi, R. Xie, M.-Y. Han, W. Yang, Chem. Mater 2014, 26, 3599-3602; d) K. Kim, C.-S. Han, S. Jeong, J. Mater. Chem. 2012, 22, 21370-21372.

[23] A. Benad, C. Guhrenz, C. Bauer, F. Eichler, M. Adam, C. Ziegler, N. Gaponik, A. Eychmüller, ACS Appl. Mater. Interfaces 2016, 8, 21570-21575. 
Entry for the Table of Contents (Please choose one layout)

\section{COMMUNICATION}

Tri(pyrazolyl)phosphanes are utilized for the convenient synthesis of longterm stable stock solutions of $\mathrm{P}(\mathrm{OLA})_{3} \quad(>6$ months, OLAH = oleylamine) for the preparation of InP/ZnS quantum dots in the spectral range between $530-620 \mathrm{~nm}$ reaching photoluminescence quantum yields between 51-62\%. The liberated pyrazoles can easily be recovered and reused contributing positively to a sustainable waste-management.

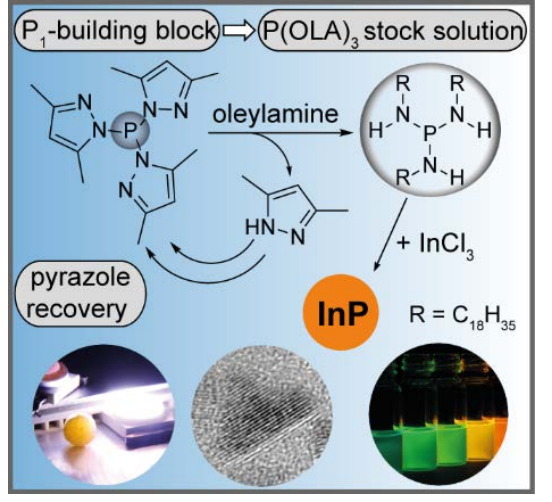

René Panzer, ${ }^{[a]}$ Chris Guhrenz, ${ }^{[b]}$

Danny Haubold, ${ }^{[b]}$ René Hübner, ${ }^{[c]}$

Nikolai Gaponik, ${ }^{[b]}$ Alexander

Eychmüller, ${ }^{*[b]}$ and Jan J. Weigand ${ }^{*[a]}$

Page No. - Page No.

Versatile Tri(pyrazolyl)phosphanes Application as phosphorus precursors for the synthesis of highly emitting InP/ZnS quantum dots 